\title{
O DIREITO À EDUCAÇÃO BÁSICA NO PARAGUAI
}

\author{
EL DERECHO A LA EDUCACIÓN BÁSICA EN EL PARAGUAY
}

THE RIGHT TO BASIC EDUCATION IN PARAGUAY

\author{
Kellcia Rezende SOUZA ${ }^{1}$ \\ Mara Lucinéia Marques Corrêa BUENO²
}

\begin{abstract}
RESUMO: O presente trabalho objetiva compreender a proteção normativa do direito à educação básica no Paraguai. Para tanto, foi realizada uma pesquisa bibliográfica e documental com enfoque qualitativo. A fonte documental foi constituída pelos seguintes documentos: Constituição vigente do Paraguai e Legislação educacional (Lei de Diretrizes e Bases e/ou legislação equivalente). Foram contempladas nesses documentos a análise das categorias referentes à obrigatoriedade, gratuidade, financiamento e organização dos sistemas de ensino. A escolarização obrigatória e gratuita no Paraguai totaliza nove anos de duração (6 aos 14 anos) e está restrita à educação básica escolar. No que concerne ao financiamento, o Paraguai delimita a focalização de gastos e também prevê, legalmente, a isenção de impostos para as instituições privadas. Já o sistema de ensino está estruturado em educação inicial (0 à 5 anos); educação básica escolar (6 à 14 anos) e Educação Média (14 à 17 anos).
\end{abstract}

PALAVRAS-CHAVE: Direito a educação. Paraguai. Política educacional.

RESUMEN: El presente trabajo tiene como objetivo comprender la protección normativa del derecho a la educación básica en Paraguay. Para ello, se realizó una investigación bibliográfica y documental con enfoque cualitativo. La fuente documental fue constituida por los siguientes documentos: Constitución vigente del Paraguay y Legislación educativa (Ley de Directrices y Bases y / o legislación equivalente). Se contemplaron en estos documentos el análisis de las categorías referentes a la obligatoriedad, gratuidad, financiamiento y organización de los sistemas de enseñanza. La escolarización obligatoria y gratuita en Paraguay totaliza nueve años de duración (6 a 14 años) y está restringida a la educación básica escolar. En lo que concierne al financiamiento, Paraguay delimita la focalización de gastos y también prevé, legalmente, la exención de impuestos para las instituciones privadas. El sistema de enseñanza está estructurado en educación inicial (0 a 5 años); educación básica escolar (6 a 14 años) y Educación Media (14 a 17 años).

PALABRAS CLAVE: Derecho a la educación. Paraguay. Política educativa.

\footnotetext{
${ }^{1}$ Universidade Federal da Grande Dourados (UFGD), Dourados - MS - Brasil. Professora Doutora da Faculdade de Educação. ORCID: <https://orcid.org/0000-0002-8663-4615>. E-mail: kellcia@hotmail.com

${ }^{2}$ Universidade Federal da Grande Dourados (UFGD), Dourados - MS - Brasil. Doutoranda do Programa de Pós-Graduação em Educação/Faculdade de Educação. ORCID: <https://orcid.org/0000-0002-57859727>. E-mail: maramarquesamm@gmail.com
} 
ABSTRACT: The objective of this paper is to understand the normative protection of the right to basic education in Paraguay. For this, a bibliographical and documentary research with a qualitative approach was carried out. The documentary source was constituted by the following documents: Current Constitution of Paraguay and Educational Legislation (Law of Guidelines and Bases and / or equivalent legislation). The analysis of the categories referring to the compulsory nature, free of charge, financing and organization of teaching systems was contemplated in these documents. Compulsory and free schooling in Paraguay totals nine years (6 to 14 years) and is restricted to basic school education. With regard to financing, Paraguay delimits the targeting of expenditures and also provides, legally, for tax exemption for private institutions. The education system is structured in initial education (0 to 5 years); basic school education (6 to 14 years) and secondary education (14 to 17 years).

KEYWORDS: Educational policy. Education rights. Paraguay.

\section{Introdução}

O direito à educação propiciou, historicamente, a função de ser a ponte entre os direitos políticos e os direitos sociais. Desse modo, garantir um nível mínimo de escolarização ao indivíduo torna-se um direito/dever intimamente relacionado ao exercício da cidadania.

Conforme Cury (2002), a educação deve estar assegurada em um amplo marco jurídico, de modo que potencialize não só sua garantia legal, mas, principalmente, sua garantia material, pois o usufruto desse direito representa a criação de condições individuais e coletivas para o desenvolvimento da consciência sobre a realidade em que se vive e sobre as relações existentes nos contextos dos quais os sujeitos são históricos, sociais, culturais, econômicos e políticos. Trata-se, pois, do direito que possibilita os instrumentos concretos para lograr a cidadania de maneira efetiva.

Imbuída por essa perspectiva, é importante compreender a proteção normativa do direito à educação básica no Paraguai. Para tanto, foi realizada uma pesquisa bibliográfica e documental com enfoque qualitativo. A fonte documental foi constituída pelos seguintes documentos: Constituição vigente do Paraguai e Legislação educacional (Lei de Diretrizes e Bases e/ou legislação equivalente). Foram contempladas nesses documentos a análise das categorias referentes à obrigatoriedade, gratuidade, financiamento e organização dos sistemas de ensino.

Logo, a investigação se justifica pela necessidade da realização de estudos que explorem a educação e suas relações em âmbito internacional, dada a implantação de políticas públicas educacionais na garantia do direito à educação, assim como na 
configuração e no entendimento dessas relações internacionais, dentre elas, com os demais países da América Latina.

\section{Direito à educação na legislação Paraguaia}

Ao garantir o direito à educação básica obrigatória e gratuita, o Estado passa a assegurar uma condição universal para o próprio usufruto dos direitos civis. Assim, Cury (2002) aponta que a relevância da educação primária tornada como um direito imprescindível do cidadão e um dever do Estado impuseram a obrigatoriedade e gratuidade como modos de torná-lo acessível a todos, indistintamente.

A garantia da educação básica enquanto direito decorreu de um processo histórico de lutas conduzidas por uma concepção democrática da sociedade em que se almeja a igualdade de oportunidades ou mesmo a igualdade de condições sociais e buscar essa premissa significa postular a ampliação da obrigatoriedade e gratuidade enquanto princípios que expandem a proteção do direito (CURY, 2002). Frente ao exposto, vejamos como os princípios de obrigatoriedade e gratuidade são tratados nos marcos jurídicos do Paraguai.

A Constituição do Paraguai, promulgada em 1992, versa sobre o direito à educação em seu capítulo VII, intitulado "De La Educación y De La Cultura", apontando, no artigo 73, as seguintes finalidades da educação:

Toda persona tiene derecho a la educación integral y permanente, que como sistema y proceso se realiza em el contexto de la cultura de la comunidad. Sus fines son el desarrollo pleno de la personalidad humana y la promoción de la libertad y la paz, la justicia social, la solidaridad, la cooperacíon y la integración de los pueblos; el respeto a los derechos humanos y los princípios democráticos; lá afirmación del compromiso com la Patria, de la identidad cultural y la formación intelectual, moral y cívica, así como la eliminación de los contenidos educativos de caráter discriminatorio. La erradicación del analfabetismo y la capacitación para ela trabajo son objetivos permanentes del sistema educativo (PARAGUAI, 1992).

Denota-se, nesse artigo, que o direito à educação é garantido a toda a pessoa, como um processo de formação cultural a ser desenvolvido ao longo da vida do indivíduo. Assim, deve ser materializado pela educação integral e permanente. A redação enfatiza a eliminação de todos os conteúdos educativos que podem ter caráter discriminatório e propõe a erradicação do analfabetismo bem como a capacitação para o 
trabalho como objetivos permanentes de todo o sistema educativo. $\mathrm{O}$ artigo 74 dispõe sobre o direito de aprender e a liberdade de ensinar.

Se garantizan el derecho de aprender y la igualdad de oportunidades al acceso a los beneficios de la cultura humanística, de la ciencia y de la tecnología, sin discriminación alguna. Se garantiza igualmente la libertad de enseñar, sin más requisitos que la idoneidad y la integridad ética, así como el derecho a la educación religiosa y al pluralismo ideológico (PARAGUAI, 1992).

No artigo n. 75, o texto constitucional salienta que o exercício do direito à educação é responsabilidade da sociedade e recai em particular à família, aos municípios e ao Estado. Ao atribuir o dever da educação primeiro à família e depois ao Estado, denota-se uma concepção que contrasta com a previsão da educação enquanto um bem público. Cury (2002) esclarece que, nessa vertente, o texto constitucional tende a dar margem para a diminuição do papel do Estado, o que pode resultar na inversão de responsabilidades em relação à família, colocando-a em primeiro lugar. Quanto à obrigatoriedade e gratuidade do ensino, a Carta Magna expõe no artigo 76 - Os deveres do Estado:

La educación escolar básica es obligatoria. Em lãs escuelas públicas tendrá caráter gratuito. El Estado fomentará la enseñanza media, técnica, agropecuária, industrial y la superior o universitaria, así como la investigación científica y tecnológica. La organización del sistema educativo es responsabilidad esncial del Estado, com la participación de las distintas comunidades educativas. Este sistema abarcará a los setores públicos e privados, así como al âmbito escolar y extraescolar (PARAGUAI, 1992).

A Carta Magna paraguaia prevê a obrigatoriedade da educação escolar básica ${ }^{3}$, que deverá ser oferecida gratuitamente pelos estabelecimentos públicos. A Lei Geral da Educação do Paraguai n. 1.264/1998, que dispõe de 161 artigos, também reitera os princípios assegurados na Constituição do país. Essa normativa estabelece os princípios gerais para a educação pública e, também, para a privada e salienta que a educação deve ser prioridade para a consolidação da democracia, da diminuição das desigualdades sociais e da possibilidade de novas oportunidades para toda a população (PARAGUAI, 1998).

\footnotetext{
3 “A educação escolar básica é definida pela Lei no. 1.264/1998, como obrigatória e gratuita nas escolas públicas. Destina-se a crianças de seis a quatorze anos de idade e divide-se em três ciclos de três anos de duração cada um, com duração total de nove anos" (FONTOURA, 2008, p. 77).
} 
A educação formal do país é estruturada em três níveis: o primeiro nível inclui a educação infantil e o ensino básico; o segundo nível, ensino médio; o terceiro nível, o ensino superior. A educação básica agrega nove graus e é obrigatória. Essa etapa é gratuita em escolas públicas de gestão oficial. Nesse viés, a escolarização obrigatória do país totaliza nove anos de duração e está restrita à educação básica, o que equivale, a título de comparação, ao Ensino Fundamental no Brasil e Secundário na Argentina. No artigo 32, é enfatizado que a gratuidade poderá ser estendida a outros níveis, instituições ou indivíduos, mas essa ampliação estará sujeita aos recursos do orçamento nacional (PARAGUAI, 1998).

As modalidades compreendem: a Educação básica geral e continuada (Equivalente ao EJA no Brasil); Educação para grupos étnicos, Educação camponesa e rural; Educação para pessoas com limitações e com capacidades excepcionais; Educação para a reabilitação social; Educação militar e policial; Educação para religiosos. A Lei também consta com um capítulo intitulado "A Compensação das desigualdades na educação", cujos artigos 23 e 24 ressaltam:

Art. 23 - Las autoridades educativas mediante programas de compensación, atenderán de manera preferente a los grupos y regiones que enfrentan condiciones económicas, demográficas y sociales de desventaja.

Art. 24 - Se facilitará el ingreso de las personas de escasos recursos en los establecimientos públicos gratuitos (PARAGUAI, 1998).

Os artigos destacam a desigualdade socioeconômica como uma condição que afeta o usufruto do direito à educação. Vieira (2007, p. 28) adverte que a exclusão econômica, oriunda das duradouras marginalizações sociais corrói a imparcialidade da Lei, o que pode causar a invisibilidade dos indigentes e a imunidade dos privilegiados aos olhos das instituições jurídicas. Nesse sentido, a extrema e persistente desigualdade deteriora a condição da reciprocidade da dignidade humana, "[...] tanto em seu sentido moral quanto em seu interesse mútuo que enfraquece a integridade do Estado de Direito". Em que pese esse quadro, cabe às legislações não desconsiderar o contexto das singularidades econômicas, sociais e políticas em que se materializam.

Percebemos que a legislação Paraguaia reconhece os valores da educação escolar. Para isso, reitera sua condição de formação da cidadania. Os textos legais consideram a criança em sua dignidade de pessoa humana e sujeito pleno de direito à vida, à educação, à saúde, à convivência familiar, cabendo ao Estado, família e 
sociedade o dever de garantir esses direitos, com absoluta prioridade. Isso significa que compete ao Estado formular políticas, implementar programas e viabilizar recursos que garantam à criança desenvolvimento integral e vida plena, de forma que complemente a ação da família (CURY, 2008).

No entender de Oliveira (2001), a obrigatoriedade e a gratuidade são pilares fundamentais na garantia do direito à educação à medida que resguardam a sua função eminentemente social e pública. Visualizamos que o país, no texto constitucional, assegura a obrigatoriedade e a gratuidade enquanto princípios do direito à educação básica.

Embora possamos considerar como avanços a garantia da escolaridade obrigatória e gratuita nas legislações do Paraguai, é preciso analisar outras prerrogativas legais para compreender se o direito à educação é assistido de condições concretas para sua efetivação. Nesse viés, é imperativo, no âmbito deste estudo, investigar os investimentos que são destinados à educação pelo referido Estado.

A Constituição Paraguaia estabelece, em seu artigo n. 85, denominado Orçamento Mínimo, que os recursos para a educação não poderão ser inferiores a $20 \%$ do total destinado à Administração Central, excluindo, nesse caso, empréstimos e subvenções. A Lei do Orçamento Geral da Nação que define a distribuição dos recursos é aprovada, anualmente, pelo congresso nacional, conforme artigo n. 216 da Carta Magna.

Art. 85 - Los recursos destinados a la educación en el Presupuesto General de la Nación no serán inferiores al veinte por ciento del total asignado a la Administración Central, excluidos los préstamos y las donaciones (PARAGUAI, 1992).

A Lei Geral da Educação do Paraguai n. 1264/1998 regulamenta o financiamento educacional a partir de vários artigos. $\mathrm{O}$ artigo n. 4 reitera o princípio constitucional de que o Estado tem a responsabilidade de garantir a toda a população o acesso à educação e que os recursos necessários para prover o funcionamento do Sistema Nacional de Educação serão decorrentes do Orçamento Geral da Nação.

Art. 4 - El Estado tendrá la responsabilidad de asegurar a toda la población del país el acceso a la educación y crear las condiciones de una real igualdad de oportunidades. El sistema educativo nacional será financiado básicamente con recursos del Presupuesto General de la Nación (PARAGUAI, 1998). 
A estrutura de financiamento do sistema educacional está inteiramente relacionada à organização institucional de cada país. É, por conseguinte, essencial considerar a organização política do tipo federal ou unitário e o grau de descentralização dos gastos com a educação. Para tanto, é imprescindível a definição de responsabilidade sobre o financiamento do serviço para cada um dos níveis envolvidos (TROJAN, 2010).

$\mathrm{O}$ artigo n. 146 aponta que, além dos aportes do Estado, os governos dos municípios devem destinar recursos à educação em conformidade com as políticas de descentralização e da gestão do orçamento público. Contudo, não há a fixação de percentuais mínimos, o que só ocorre, no âmbito da administração central do país, como previsto na Carta Magna.

No artigo n. 148, há a especificação da priorização dos gastos com a educação, que será dada à parcela social marginalizada, ao setor rural e as regiões de fronteira. “Art.148- En la asignación de recursos se dará prioridad a la educación de los sectores marginales de la población, al sector rural, a las áreas urbanas marginales y a las zonas fronterizas" (PARAGUAI, 1998).

No que concerne à escolaridade obrigatória do Paraguai, é regulamentada, em sua legislação, a prioridade dos recursos públicos para a população marginalizada do país. Essa característica retira do ordenamento do país o viés equitativo da perspectiva de uma educação para todos indistintamente. Denota-se, a partir do pressuposto legal, a ênfase na focalização ao invés da universalização. Como o Paraguai é um país cuja economia é pequena e o grau de desigualdade bastante acentuado, se considerarmos as demais do Mercosul, a determinação do grau de universalização ou focalização das suas políticas estarão diretamente relacionadas à definição das prioridades definidas pelo Estado, como observamos no caso do financiamento educacional (TROJAN, 2010).

Os recursos disponíveis para a implementação de políticas educacionais definem os limites das ações do Estado. Camargo (2003) aponta que, se o foco do sistema público de educação consiste no atendimento a todo e qualquer cidadão gratuitamente, $o$ aporte financeiro necessário deverá ser bem mais amplo do que se a prioridade for atender gratuitamente apenas à população que está em situação de pobreza.

Ao mesmo tempo em que a legislação paraguaia prevê políticas voltadas para a população marginalizada, a lei educacional do país, conforme artigo n. 67, também assegura recursos para o financiamento das instituições privadas de ensino, o que demonstra a relação público-privada. A transferência, nesse caso, se dará por subsídios ou pelos salários dos professores. Para o incremento dos recursos públicos deverão ser 
considerados os serviços prestados à comunidade, o nível ou classe de estabelecimento e o valor que é pago pelos usuários.

Art. 67 - El aporte de la administración del Estado para atender el funcionamiento de las instituciones educativas privadas subvencionadas o los salarios de sus educadores, será contemplado en el Presupuesto General de la Nación. Se tendrán en cuenta la función social que estas instituciones cumplen en su zona de influencia, el nivel o clase de establecimiento, los servicios que prestan a la comunidad y la cuota que perciben de sus usuários (PARAGUAI, 1998).

Sobre o financiamento das instituições privadas de ensino no Paraguai, o artigo n. 150 institui que elas estão isentas de todos os tipos de impostos. As mesmas podem apresentar anualmente, ao Ministério da Educação e Cultura, as solicitações para receberem bolsas de fundos destinadas às pessoas de baixa renda ou excepcionais propriedades intelectuais (PARAGUAI, 1998).

A focalização nos gastos pressupõe que as receitas do Estado não são suficientes para a universalização da oferta educacional gratuita. Logo, ao assumir a execução do financiamento da instituição privada traz questionamentos ao pressuposto da incapacidade de garantia universal do direito à educação. Essa premissa legal, além de demonstrar a contradição referente ao papel do Estado com a educação básica, fortalece a transferência da responsabilidade do serviço público para a iniciativa privada. Assim, a legislação, além de incentivar a responsabilização da educação para as instituições privadas, também legitima essa prerrogativa perante a sociedade. Camargo (2003) compreende que o Estado, ao alocar recursos públicos à iniciativa privada, deixa de investir nas escolas públicas.

O artigo n. 145 ratifica a previsão da Carta Magna. Segundo ele, não podem ser inferiores a $20 \%$ os recursos destinados à educação decorrentes do Orçamento Geral da Nação. O Estado, por esse orçamento, irá prover os recursos necessários para o funcionamento do Ministério da Educação e Cultura e das instituições públicas, bem como para a criação de novos estabelecimentos de ensino, dos subsídios para as instituições privadas e, na medida do possível, para o desenvolvimento educacional sustentável e formação contínua dos professores. Esse texto sintetiza as previsões já firmadas nos demais artigos da referida legislação. 
Art. 145 - La asignación presupuestaria para la educación, en ningún caso podrá ser menor al veinte por ciento del Presupuesto General de Gastos de la Nación. El Estado, por medio de dicho presupuesto, proveerá los bienes y recursos necesarios para:

a) el funcionamiento del Ministerio de Educación y Cultura y el Consejo Nacional de Educación y Cultura, la investigación educativa y los demás servicios del Ministerio;

b) el funcionamiento, equipamiento, mantenimiento y desarrollo de los establecimientos educativos públicos;

c) la creación de nuevas instituciones educativas públicas;

d) el crecimiento vegetativo del sistema educativo nacional en el ámbito de la educación formal, de la no formal y de la refleja;

e) las ayudas convenidas a las instituciones privadas, en lo previsto en esta ley; y,

f) cuanto sea necesario para el desarrollo educativo sostenible y la actualización permanente de las educadoras y educadores y del sistema educativo nacional en general (PARAGUAI, 1998).

Como podemos observar, os recursos para a educação não poderão ser inferiores a $20 \%$ do total da administração central e devem constar na Legislação referente ao orçamento nacional, visando, desse modo, assegurar o dever do Estado para com a educação de todos. Os recursos são destinados ao Ministério de Educação e Cultura que os redistribui aos departamentos a partir de ação conjunta com os governos legais. Nesse caso, não há fixação na legislação de percentuais específicos para os departamentos.

No que tange à disponibilidade de recursos financeiros investidos na educação no país, notamos que os recursos fiscais são as principais fontes de financiamento. Em especial, por ser um Estado Unitário, o Paraguai depende, principalmente, da arrecadação de impostos concentradas ao nível do governo central. Identificamos, também, que as legislações do país vinculam um percentual de recursos específicos destinado à educação. No entender de Cury (2002), a mola insubstituível que põe em marcha o direito à educação deve ser a ação responsável do Estado e suas obrigações, e como esse direito não pode ser efetivado sem os recursos necessários, é indispensável que esteja consignado, preferencialmente na Lei Maior, à fonte desses investimentos.

O aparato legal deve ter como marco a Constituição Federal de um país, que é o principal instrumento jurídico para a construção da normatividade e, consequentemente, para a proteção do direito às atividades educativas. O financiamento educacional, ao não ser assistido pelo texto constitucional, tende a ter limites, sobretudo no que tange à vulnerabilidade das legislações, que são alteradas ou suprimidas conforme a temporalidade de um governo (CURY, 2002). 
O Paraguai, em seus marcos regulatórios, incentiva a prestação de serviços educacionais por instituições privadas. No Paraguai, além da exoneração de tributos para estas instituições, há a previsão legal da destinação do orçamento público para as instituições de ensino particulares. Para Fernandes, Brito e Peroni (2012), o financiamento educacional, ao mesmo tempo em que representa possibilidades ou limites para a concretização do direito à educação, desvela, também, os liames que assolam as relações entre o público e o privado. Essa relação revela, principalmente, as contradições no que tange às prioridades do Estado. Historicamente, os Estados que injetam recursos públicos no setor privado educacional tendem a administrar o setor com escassez de recursos, impactando, diretamente, a garantia do direito a uma educação pública e gratuita.

A proteção institucional da garantia do direito à educação também está intimamente atrelada à organização dos sistemas de ensino no país. Dourado e Oliveira (2009) enfatizam que a estruturação de um sistema educacional representa uma grande conquista para a educação e traz desdobramentos diretos para a efetivação desse direito. Desse modo, é relevante compreendermos como é organizado o sistema de ensino do Paraguai.

A Constituição Federal do Paraguai atribui como responsáveis pela educação a sociedade, em particular a família, o município e o Estado. O artigo n. 76 da Carta Magna do país, além de ressaltar que a educação básica é obrigatória e que o Estado deve promovê-la, bem como a educação secundária, técnica, agrícola, industrial e de ensino superior, registra que a organização do sistema de ensino é responsabilidade essencial do Estado, com a participação de diferentes comunidades educativas. Esse sistema irá abranger os setores público e privado, tanto no nível formal quanto informal (PARAGUAI, 1992).

O texto constitucional ainda estabelece as competências do governo departamental e dos municípios. O artigo n. 163 prevê a coordenação das ações dos departamentos em consonância com as atividades do governo central no que tange à saúde e à educação. O artigo n. 168, por sua vez, regulamenta que os municípios do país dispõem da atribuição da livre gestão da educação (PARAGUAI, 1992).

Embora a Carta Magna do país delimite responsabilidades aos departamentos e municípios, a organização, financiamento e avaliação do sistema de ensino no Paraguai são incumbências do Estado. A centralização das competências educacionais para o Estado contrasta com a perspectiva constitucional que, em seu artigo primeiro, define 
que o país é um Estado Unitário Descentralizado. Podemos depreender, conforme Trojan (2010), que a legislação que versa sobre a educação do Paraguai demonstra uma perspectiva de descentralização administrativa, ou seja, de distribuição da execução das decisões políticas tomadas pelo governo central.

A Lei Geral da Educação n. 1.264/1998 regulamenta o sistema educacional do país e seus respectivos objetivos. A referida lei também estabelece, em seus artigos n. 5 e 6, que o sistema educacional paraguaio definirá as diretrizes curriculares básicas voltadas à educação básica e as modalidades de ensino, e destaca que o Estado promoverá a descentralização dos serviços educacionais públicas.

Art. 5 - Através del sistema educativo nacional se establecerá un diseño curricular básico, que posibilite la elaboración de proyectos curriculares diversos y ajustados a las modalidades, características y necesidades de cada caso.

Art. 6 - El Estado impulsará la descentralización de los servicios educativos públicos de gestión oficial (PARAGUAI, 1998).

Ainda que o artigo n. 6 enfatize a previsão da adoção de uma política de favorecimento à descentralização dos serviços educacionais para as autoridades locais, o sistema nacional de educação do Paraguai é centralizado no que se refere à tomada de decisões, ao financiamento, à avaliação, à gestão e a sua respectiva operacionalização (TROJAN, 2010).

$\mathrm{O}$ artigo n. 12 reitera as premissas regulamentadas na Constituição paraguaia da responsabilidade do Estado com a organização do sistema nacional. Já o artigo n. 27 define a estruturação formal da educação do país em três níveis: o primeiro compreende a educação inicial e educação escolar básica, que é obrigatória; o segundo contempla a educação média e o terceiro, a educação superior (PARAGUAI, 1998). O Quadro 1 ilustra a referida organização.

Art. 12 - La organización del sistema educativo nacional es responsabilidad del Estado, con la participación según niveles de responsabilidad de las distintas comunidades educativas. Este sistema abarca a los sectores público y privado, así como al ámbito escolar y extraescolar [...].

Art. 27 - La educación formal se estructura en tres niveles: El primer nivel comprenderá la educación inicial y la educación escolar básica; el segundo nivel, la educación media; el tercer nivel, la educación superior (PARAGUAI, 1998). 
Quadro 1 - Estrutura sistema de ensino do Paraguai

\begin{tabular}{|c|c|c|c|}
\hline Níveis de Ensino & Ciclos & Idade dos Alunos & Modalidades \\
\hline \multirow[t]{3}{*}{ Educação Inicial } & Maternal & 0 a 03 anos & \multirow{8}{*}{$\begin{array}{c}\text { Educação básica } \\
\text { geral e continuada; } \\
\text { Educação para } \\
\text { grupos étnicos, } \\
\text { Educação } \\
\text { camponesa e rural; } \\
\text { Educação para } \\
\text { pessoas com } \\
\text { limitações e com } \\
\text { capacidades } \\
\text { excepcionais; } \\
\text { Educação para a } \\
\text { reabilitação social; } \\
\text { Educação militar e } \\
\text { policial; } \\
\text { Educação para } \\
\text { religiosos }\end{array}$} \\
\hline & Infantil & 03 a 04 anos & \\
\hline & Pre-escolar & 05 anos & \\
\hline \multirow{3}{*}{$\begin{array}{c}\text { Educação Escolar } \\
\text { Básica }\end{array}$} & Primeiro ciclo & 06 a 08 anos & \\
\hline & Segundo ciclo & 09 a 11 anos & \\
\hline & Terceiro ciclo & 12 a 14 anos & \\
\hline Educação Média & $\begin{array}{c}\text { Bacharelado } \\
\text { científico e técnico }\end{array}$ & 14 a 17 anos & \\
\hline Educação Superior & $\begin{array}{l}\text { Universitária e Pós- } \\
\text { Graduação }\end{array}$ & A partir de 18 anos & \\
\hline
\end{tabular}

Fonte: Elaboração própria com base em Paraguai (1998).

A educação inicial do Paraguai compreende três ciclos - maternal, infantil e préescolar - e é voltado para as crianças de zero a cinco anos. Já a educação escolar básica do país contempla nove graus e é dividida em três ciclos de três anos de período. A formação da educação média ocorre em um único ciclo com três anos de duração e voltada para as opões de bacharelado científico e técnico profissionalizante (PARAGUAI, 1998).

Além dos três níveis, o sistema paraguaio também regulamenta a pós-graduação e as seguintes modalidades educacionais: a Educação básica geral e continuada; Educação para grupos étnicos, Educação camponesa e rural; Educação para pessoas com limitações e com capacidades excepcionais; Educação para a reabilitação social; Educação militar e policial; Educação para religiosos (PARAGUAI, 1998).

Segundo Molinier (2014, p. 17), os instrumentos legais do Paraguai (Constituição de 1992 e da Lei Geral da Educação de 1998) foram marcos institucionais que regulamentaram a histórica reivindicação de um sistema nacional de educação unificado como a base para um projeto democrático voltado para assegurar o direito à educação. "El marco normativo nacional paraguayo para asegurar el cumplimiento del 
derecho a la educación, consagrado constitucionalmente y canalizado con diferentes instrumentos jurídico-institucionales como base de un proyecto democrático posible”.

Arelalo (1999) esclarece que o sistema é uma realidade educacional complexa e, muitas vezes, extremamente diversificada para muitos países, sobretudo os de dimensão territorial. Isso significa que depende da própria consolidação da organização da forma de Estado para que adquira unidade, coerência e sentido. Trata-se, pois, de sistematizálo a partir de marcos normativos e, especialmente, gerar condições estruturais para sua operacionalização seja no modelo de composição do estado federal, unitário, de comunidades autônomas.

Trojan (2010) aponta que os Estados unitários editam o marco legal completo e formulam a política nacional para todo o país. As divisões territoriais (Departamentos, Províncias, Distritos, Municípios ou outro nome que adotem) colaboram nesse processo, mas não constituem esferas independentes de decisão legislativa e política. Sem destoar do sistema político-administrativo de Estado Unitário, o governo da República do Paraguai, como mostram seus respectivos ordenamentos legais, têm buscado englobar, progressivamente, os governos departamentais na provisão das decisões atinentes à educação básica.

O país também prevê o oferecimento de modalidades diferentes de ensino voltadas para as necessidades específicas de determinados segmentos populacionais, objetivando consagrar a igualdade no direito à educação, atendendo, dessa forma, às particularidades de indivíduos ou grupos de caráter permanente ou temporal. Essas modalidades são oferecidas dentro dos níveis e/ou etapas de ensino mencionadas, devendo cumprir os requisitos previstos nas legislações específicas para cada uma delas.

O reconhecimento do Estado como responsável pelo direito à educação implica, também, na existência de mecanismos de controle público sobre as políticas de sistematização e institucionalização desse papel. Cabe ainda, ao Estado, implantar instrumentos de reparação de violações do direito à educação e possibilitar o acesso a esses instrumentos - tanto os nacionais quanto outros, de âmbito regional e internacional - a todos e todas. "Todo esse conjunto de implicações relacionadas ao papel do Estado na garantia do direito à educação conduz à centralidade do fortalecimento dos sistemas públicos de educação" (CROSO; MAGALHÃES, 2016, p. 19).

As autoras também destacam ser primordial que os sistemas públicos de educação dos países sejam fortalecidos a partir da compreensão de que a educação é um bem de 
sentido público e da concepção da educação como Direito Humano fundamental. A educação é, em si mesma, um espaço privilegiado de formação de sujeitos capazes de promover o desenvolvimento de uma nação, mas, para isso, os próprios sistemas educativos devem ser promotores de igualdade e cidadania.

\section{Considerações finais}

No contexto paraguaio, o direito à educação foi sendo consolidado na Constituição e na legislação infraconstitucional a partir dos seus respectivos delineamentos políticos, sociais, econômicos e culturais. Se considerarmos que a maioria dos países da América Latina passou por recentes momentos de redemocratização, uma vez que vivenciaram longos períodos ditatoriais, no âmbito normativo, há um avanço progressivo, o que permitiu, mesmo com as limitações evidenciadas, a consolidação de um ordenamento jurídico educacional.

A garantia do direito educacional está assegurado no texto constitucional, no qual é contemplada a sua obrigatoriedade e a gratuidade. A escolarização obrigatória totaliza nove anos de duração (6 aos 14 anos) e está restrita à educação básica, o que equivale, a título de comparação, ao Ensino Fundamental no Brasil. No que concerne ao financiamento, o Paraguai delimita a focalização de gastos, o que indica que as receitas do Estado não são suficientes para todas as etapas educacionais. Além disso, também prevê legalmente a isenção de impostos para as instituições privadas. Já o sistema de ensino está estruturado em educação inicial (0 à 5 anos); educação básica escolar (6 à 14 anos) e Educação Média (14 à 17 anos).

Nessa vertente, podemos inferir que há um extenso caminho a se percorrer para a ampliação normativa de proteção ao direito à educação básica no Paraguai, no qual haja o provimento de instrumentos jurídicos que dê mais garantias de acesso, permanência e qualidade. É crucial ponderar que a prerrogativa do direito à educação de qualidade é dinâmica e distinta, pois vai representar as demandas históricas de um dado país.

Devido à abrangência do tema, reconhecemos que há um extenso campo de investigação aberto para que se possa aprofundar e produzir conhecimento novo sobre essa temática. Portanto, é imprescindível a realização de estudos que investiguem a efetivação do direito à educação nos países da América Latina, como fenômeno a ser 
interrogado na perspectiva de uma análise política, sociológica e pedagógica, objetivando avançar na busca de uma efetiva educação de qualidade para todos.

\section{REFERÊNCIAS}

ARELARO, L. R. G. Concepção de sistema de ensino no Brasil e competências legais do sistema municipal. Campinas: Editora mimeo, 1999.

CURY, C. R. J. Direito à educação: direito à igualdade, direito à diferença. Cadernos de Pesquisa, São Paulo, n. 116, p. 245-262, jul., 2002.

CURY, C. R. J. A educação básica como direito. Cadernos de pesquisa, São Paulo, v. 38, n. 134, p. 292-303, 2008.

PARAGUAI. Constitución de la República de Paraguay. Assunción. 1992.

CURY, C. R. J. Ley n. 1.264 del 26 mayo 1998. Ley General de Educación. Assunción, 1998.

CAMARGO, J. M. Gastos sociais: focalizar versus universalizar. In: IPEA. Políticas sociais: acompanhamento e análise. 7 ed. Rio de Janeiro: IPEA, 2003.

CROSO, C.; MAGALHÃES, G. M. Privatização da educação na América Latina e no Caribe: tendências e riscos para os sistemas públicos de ensino. Educação e Sociedade, Campinas, v. 37, n. 134, p. 17-33, 2016.

DOURADO, L. F.; OLIVEIRA, J. F. A qualidade da educação: perspectivas e desafios. Cadernos Cedes, Campinas, 29, n. 78, p. 201-215, 2009.

FERNANDES, M. D. E.; BRITO, S. H. A. de; PERONI, V. M. V. Sistema e plano nacional de educação: notas sobre conceituação, relação público-privado e financiamento. Revista Brasileira de Estudos Pedagógicos, Brasília, v. 93, n. 235, p. 565-578, 2012.

FONTOURA, J. B. A harmonização do sistema de educação no âmbito do Mercosul. Belo Horizonte, 2008. Dissertação (Mestrado em Direito) - Faculdade de Direito, Pontífice Universidade Católica de Minas Gerais, Belo Horizonte, 2008.

MOLINIER, L. El Sistema educativo obligatorio y gratuito em paraguay: fundamentos para sua universalización y calificación. In: ORTIZ, L. (Org.). La educación en su entorno: Sistema educativo y políticas públicas en Paraguay. Assuncion: CADEP, 2014. p. $15-56$.

OLIVEIRA, R. P. O direito à educação. In: O., R. P.; ADRIÃO, T. (Orgs.). Gestão, financiamento e direito à educação: análise da LDB e da Constituição Federal. São Paulo: Xamã, 2001. p. 15-44. 
TROJAN, R. M. Estudo comparado sobre políticas educacionais na América Latina e a influência dos organismos multilaterais. Revista Brasileira de Política e Administração da Educação, Brasília, v. 26, n. 1, p. 55-74, jan./abr., 2010.

VIEIRA, Oscar Vilhena. A desigualdade e a subversão do Estado de Direito. Sur.

Revista Internacional de Direitos Humanos, v. 4, n. 6, p. 28-51, 2007.

\section{Como citar este artigo:}

SOUZA, Kellcia Rezende.; BUENO, Mara Lucinéia Marques Corrêa. O direito à educação básica no Paraguai. Revista Ibero-Americana de Estudos em Educação, Araraquara, v. 13, n. 4, p. 1536-1551, out./dez., 2018. E-ISSN: 1982-5587. DOI: 10.21723/riaee.unesp.v13.n4.out/dez.2018.11759

Submissão em: 20/05/2018

Revisões requeridas: $30 / 06 / 2018$

Aprovação final em: 26/07/2018 